Eduardo Algranti ${ }^{1}$

Mina Kato ${ }^{2}$

${ }^{1}$ Editor científico

2 Editora associada

\section{Identificação, prevenção e notificação de riscos bioló- gicos no trabalho: ainda há muito que melhorar}

\author{
Identification, prevention, and notification of Biological \\ Risks at Work: still a lot to be improved
}

Este número da RBSO apresenta oito artigos, um relato de experiência, duas comunicações breves e uma resenha. Embora não inclua um dossiê temático, coincidentemente três trabalhos são relacionados a riscos biológicos no ambiente de trabalho. Dois referem-se a acidentes com perfurocortantes, porém com objetivos de análise distintos: o trabalho de Machado e Machado (p. 274-281), voltado para a ocorrência de acidentes e sua notificação em um hospital público do Centro-Oeste, e o trabalho de Silva, Machado, Santos e Marziale (p. 265-273), abordando a falta de padronização de notificação de acidentes ocorridos em unidades pertencentes a uma mesma fundação pública, com propostas concretas de melhoria desta situação. O terceiro trabalho, de Silva, Santos, Reis e Lima, enfoca o conhecimento dos profissionais de saúde acerca da hepatite B (VHB) e o estado vacinal contra esse vírus em um hospital público do Nordeste (p. 258-264).

Os riscos biológicos no trabalho foram contemplados pela Norma Regulamentadora 32 - NR32 (BRASIL. Ministério do Trabalho e Emprego. Portaria $\mathrm{n}^{\mathrm{0}} 485$, de 11 de novembro de 2005. Aprova a Norma Regulamentadora nº 32 - Segurança e Saúde no Trabalho em Estabelecimentos de Saúde. Diário Oficial [da] República Federativa do Brasil, Brasília, DF, 16 nov. 2005. Disponível em: <http://portal.mte.gov.br/data/files/FF8080812BE914E6012BF2F4BD1942F9 /p_20051111_485.pdf>. Acesso em: 02 dez. 2011). Nesta, registros de atendimento e serviços de vigilância epidemiológica são listados como importante fonte de identificação de riscos biológicos para a adoção de medidas de prevenção primária e secundária adequadas a cada situação. Estes registros e serviços devem ser organizados de forma aproveitável e devem ser confiáveis.

Da mesma forma, tanto o Manual sobre exposição a materiais biológicos do Ministério da Saúde [BRASIL. Ministério da Saúde. Exposição a materiais biológicos. Brasília: MS, 2006. (Série A. Normas e Manuais Técnicos - Saúde do Trabalhador; 3. Protocolos de Complexidade Diferenciada). Disponível em: < http:// bvsms.saude.gov.br/bvs/publicacoes/protocolo expos mat biologicos.pdf $>$. Acesso em: 02 dez. 2011], quanto a NR32 colocam a vacinação contra o VHB como uma recomendação de serviço a ser oferecido a todo profissional de saúde. No entanto, sabemos que isto ocorre ainda de forma aleatória e desordenada, tanto nos serviços públicos, quanto nos privados. Dentre as doenças virais transmissíveis por contaminação acidental, a Hepatite B apresenta alta infectividade (estima-se entre 6\% a 30\%) quando o paciente apresenta positividade para o AgHBe (MEDEIROS, E. A. S. 
Risco ocupacional. In: VERONESI, R.; FOCACCIA, R. Tratado de infectologia. 3.ed. Rio de Janeiro: Atheneu, 2005. p. 1840-1848). A prevenção secundária de acidentes com sangue contaminado com o VHB é disponível, porém sua efetividade é limitada à administração de imunoglobulina específica e ao início de vacinação dentro das primeiras 6 horas do acidente. Se o profissional de saúde é vacinado e tem resposta vacinal, isto não se faz necessário. Além disso, o VHB relaciona-se à alta incidência de câncer hepático. Portanto, a vacinação contra o VHB deveria ser compulsória para os profissionais de saúde.

Recentemente, foi divulgado um levantamento acerca das notificações encaminhadas ao Sistema de Informação de Agravos de Notificação (Sinan) referente a acidentes de trabalho com exposição potencial a riscos biológicos (CENTRO COLABORADOR EM VIGILÂNCIA DOS ACIDENTES DE TRABALHO. Acidentes de trabalho com exposição potencial a material biológico. Boletim Epidemiológico - Informe do Centro Colaborador UFBA/ISC/PISAT - MS/DSAST/CGSAT. Salvador, ano 1, n. 3, out. 2011. Disponível em: <http://www.2pontos.net/preview/pisat/hp/upload/boletim3_end.pdf>. Acesso em: 02 dez. 2011). O boletim demonstra um expressivo aumento no número de notificações no período de 2007 a 2010, analisa sua distribuição e as taxas de incidência no país, assim como as condutas tomadas em decorrência dos acidentes, e aponta caminhos necessários para uma prevenção efetiva da sua ocorrência.

A saúde e segurança de trabalhadores do setor de saúde é objeto de atuação da área de saúde do trabalhador da Organização Mundial da Saúde (OMS), colocada como prioridade dentro do Objetivo 1 do Programa Global de Saúde do Trabalhador. Os temas aqui apresentados estão entre os tópicos sugeridos para submissão de projetos através dos centros colaboradores em saúde ocupacional para o período de 2013-2017 (Disponível em: < http://www.who.int/occupational_health/network/priorities.pdf>), oferecendo oportunidades para realização de mais pesquisas sobre o tema. 